This item was submitted to Loughborough's Research Repository by the author.

Items in Figshare are protected by copyright, with all rights reserved, unless otherwise indicated.

\title{
Analysis of responsible sourcing performance in BES 6001 certificates
}

\section{PLEASE CITE THE PUBLISHED VERSION}

http://dx.doi.org/10.1680/ensu.14.00024

\section{PUBLISHER}

(c) Institution of Civil Engineers

\section{VERSION}

VoR (Version of Record)

\section{LICENCE}

CC BY-NC-ND 4.0

\section{REPOSITORY RECORD}

Upstill-Goddard, James D., Jacqueline Glass, Andrew R.J. Dainty, and lan Nicholson. 2019. "Analysis of Responsible Sourcing Performance in BES 6001 Certificates”. figshare. https://hdl.handle.net/2134/17762. 


\section{Analysis of responsible sourcing performance in BES 6001 certificates}

1 James Upstill-Goddard MSC, AIEMA Research Engineer, Responsible Solutions Ltd, Loughborough, UK

2 Jacqui Glass BA (Hons), DipArch, DipBRS, PhD, FHEA, MCIOB Professor of Architecture and Sustainable Construction, School of Civil and Building Engineering, Loughborough University, Loughborough, UK
3 Andrew R. J. Dainty BSC, PGCE, PhD, MCIOB, MASCE Professor of Construction Sociology, School of Civil and Building Engineering, Loughborough University, Loughborough, UK

4 Ian Nicholson BSC (Hons), MSC, CQP, MCQI, FICE, AIEMA Managing Director, Responsible Solutions Ltd, Loughborough, UK
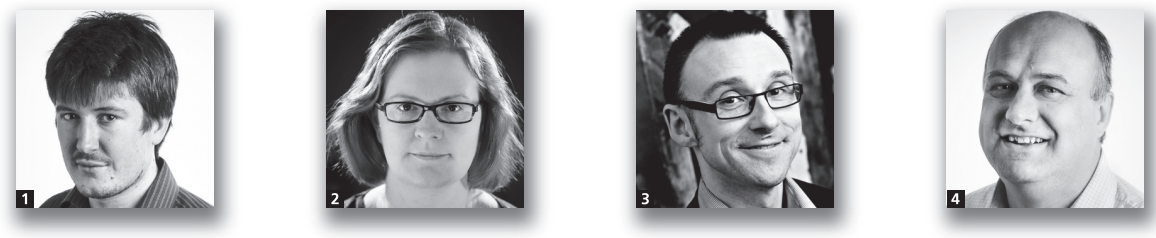

Responsible sourcing (RS) of materials is defined as the ethical management of sustainability issues within the construction supply chain, and engagement is typically evidenced by certification to BES 6001, the framework standard for the RS of construction products. Points are scored in BES 6001 under a number of clauses, yet little is known about RS practices. The aim of this study was to extract knowledge about RS practices from all 138 BES 6001 certificates issued to UK companies between 2008 and 2013. Data by performance rating, company size and product sector were analysed using Spearman's rho $(\rho)$ and Cronbach's alpha $(\alpha)$. Performance against the life cycle assessment and resource use clauses was found not to influence overall performance significantly, so neither of these clauses can be assumed to represent good summary measures of sustainability performance. This suggests that a refocusing of the scope of both these clauses might be appropriate in future developments of the standard.

\section{Notation}

$\rho$

$\alpha$
Spearman's correlation coefficient

Cronbach's alpha

\section{Introduction}

The construction industry plays a key role in sustainable development (Sev, 2009), not least because the sector contributes around $7 \%$ of UK gross domestic product (GDP) (BIS, 2013). A major part of this is the construction products sector, which has an annual turnover of over $£ 50$ billion and contributes around $4 \cdot 5 \%$ to UK GDP (CPA, 2014). It provides essential materials for buildings, roads and highways and other infrastructure, and contributes around one-third of total construction output and 10\% of manufacturing output in the UK (CPA, 2014). Industry targets, such as those in the strategy for sustainable construction (BERR, 2008), have shifted the focus towards embodied impacts, as well as operational impacts across the life cycle of a material, building or asset. Ghumra et al. (2011) report that assessment schemes such as the Building Research Establishment Environmental Assessment Method (Breeam) (BRE, 2011) and the Code for Sustainable Homes (CfSH) (DCLG, 2006) have directed this focus towards the

built environment. Of particular relevance, as clients seek to maximise points in these schemes, is the traceability of materials used in construction, such that provenance is transparent and clearly communicated. Transparency (in this particular, supply chain focused, context) can be said to be obtained when all environmental and social impacts associated with that product are understood and communicated to stakeholders. One means of demonstrating this is through engaging with the concept of responsible sourcing (RS), which aims to demonstrate transparency with regard to the materials within a product. However, little is known about RS in practice. This research therefore explored how the construction industry is approaching the RS agenda through an analysis of performance of RS certificates.

\section{Context}

Responsible sourcing of construction products provides a means of managing sustainability issues associated with a product's supply chain, often from an ethical perspective (Glass, 2011). The 2008 strategy for sustainable construction (BERR, 2008) set a national target of procuring $25 \%$ of construction materials from approved RS schemes by 2012. RS encourages organisations to examine, in greater detail, the transparency of 
Engineering Sustainability

Volume 168 Issue ES2
Analysis of responsible sourcing

performance in BES 6001

certificates

Upstill-Goddard, Glass, Dainty and

Nicholson constituent materials in products, and strives to eliminate negative social and environmental impacts from the supply chain. A key driver for engagement is that use of materials from $\mathrm{RS}$ schemes is recognised through credits in Breeam, CfSH and Ceequal (the sustainability assessment, rating and awards scheme for civil engineering) (Ceequal, 2013). In 2008, the Building Research Establishment (BRE) launched BES 6001 (BRE, 2008), the framework standard for the RS of construction products, with a second version launched a year later (BRE, 2009). To date, around 70 companies have obtained over 100 certificates for a range of different products (BRE, 2014a). Although RS engagement and certifications have increased in recent years, Young and Osmani (2013) report that literature on RS remains sparse and, furthermore, Glass (2011) and Glass et al. (2012) have highlighted the lack of a research agenda to drive awareness within industry and academia. Fundamentally, understanding of how to apply the concept appears limited in some sectors, and once an organisation has become BES 6001 certified (BRE, 2008, 2009), the detail of how the organisation has scored against each clause in the standard and also how this might compare with similar products or organisations is not made public or shown on issued RS certificates. Communication of performance in such detail may result in improvements in understanding RS and application of BES 6001 (BRE, 2008, 2009) to different types of construction organisations.

The construction products sector is diverse and broad in nature; clearly, RS practices will differ between individual product sectors. For example, around $92 \%$ of the concrete industry (SCF, 2012) and 90\% of the brick sector (BDA, 2012) are BES 6001 certified. However, for other sectors, details of RS practices are limited, as suggested by evidence from the Green Book Live (BRE, 2014b), an online reference source for environmental products and services. This can be attributed to differing approaches between sectors. For example, the concrete industry has online resources (TCC, 2014) and industry guidance to support its constituent organisations in achieving BES 6001 (BRE, 2008, 2009) certification (SCF, 2010). By contrast, if sustainability publications from, for example, the natural stone sector are considered (SFGB, 2012a, 2012b), there is relatively little information on RS and how firms might go about implementing RS practices, especially those categorised as small and medium sized enterprises (SMEs). It is widely accepted in the literature that SMEs tend to have limited access to resources to drive forward sustainability initiatives (e.g. Lee and Klassen, 2008) when compared with larger organisations, and yet figures quoted for the RS certified portion of the concrete industry suggest considerable engagement from the SME community.

Despite the burgeoning interest in RS, empirical studies of performance against a certification standard are sparse. By undertaking such research, a more rounded understanding of
RS practices (between differing sub-sectors and between SMEs and non-SMEs) within the construction industry could be obtained. This would provide an improved understanding of how companies approach the standard and scoring patterns within RS certification.

\section{Background and hypotheses}

BES 6001 (BRE, 2008, 2009) is a points-based standard organisations are awarded points depending on the level of compliance demonstrated under each clause. The standard is split into three sections (see Table 1) but, for scoring purposes, it is split into two

the total score achieved in section 3.2 for organisational management requirements and section 3.3 for supply chain management requirements

total score achieved in section 3.4 for environmental and social requirements.

It has a number of compulsory and optional elements, under which points are scored depending on the level of compliance. Depending on the number of points that are scored, organisations are awarded a grade of 'pass', 'good', 'very good' or 'excellent'. Although certificates that were issued under both versions 1 and 2 of BES 6001 (BRE, 2008, 2009) were considered in this study, the majority fall under version 2 , so this is the main focus. The key difference between the two versions is the scoring of clause 3.4 .6 for life cycle assessment (LCA) (see Table 1), where three points had been available in part (a) of the clause in version 1 , but this was dropped to two points in version 2 .

In total, nine points are available in sections 3.2 and 3.3 , and 39 points are available in section 3.4. Table 2 indicates how many points are required in each section to be awarded each overall assessment score (OAS). The organisation's OAS is given by the lowest score achieved, so, for example, if an organisation achieves a 'good' level of attainment (LOA) in sections 3.2 and 3.3 and a 'pass' LOA in section 3.4, then the LOA would be 'pass' (BRE, 2009).

As Table 2 indicates, to score an excellent LOA, it is only permissible to drop one point in sections 3.2 and 3.3, and only three points in section 3.4. So, an organisation aiming for an excellent LOA must achieve maximum points in most clauses. Conversely, for organisations that achieved a pass or good LOA, there are a number of permutations for scoring the points required. Therefore, there is potential for variation in how organisations score points. The design of certificates (see BRE, 2014b) gives no indication as to how organisations achieved their LOA, which limits understanding of performance in BES 6001 (BRE, 2008, 2009) certificates and, particularly with pass or good certificates, what clauses (if any) in which the 
3.2 Organisational management requirements

3.2.1 Responsible sourcing policy

3.2.2 Legal compliance

3.2.3 Quality management system

3.2.4 Supplier management system

3.3 Supply chain management requirements

3.3.1 Material traceability through the supply chain

3.3.2 Environmental management systems in the supply chain

3.3.3 Health and safety management systems in the supply chain

\subsection{Environmental and social requirements}

3.4.2 Greenhouse gas emissions

3.4.3 Resource use

3.4.4 Waste management

3.4.5 Water extraction

3.4.6 Life cycle assessment

3.4.7 Transport impacts

3.4.8 Employment and skills

3.4.9 Local communities
(a) Compulsory (C)
(b) 1 point

C

C

C

ISO 9001 certified

C
(a) Compulsory (C)
(b) 1 point
C; $60 \%$ traceability
$75 \%$ traceability
(c) 2 points
(d) 3 points

$60 \%$ traceable to ISO

C; Established 3.3.1

14001 sites

C; Established 3.3.1

$60 \%$ traceable to traceability to OHSAS 18001 sites health \& safety (BSI, 2007) management system
(a) Policy/metrics

(b) Objectives/targets

(c) Reporting

(d) External

$75 \%$ traceable $90 \%$ traceable to ISO 14001 sites to ISO 14001 $75 \%$ traceable $90 \%$ traceable to OHSAS 18001 to OHSAS sites 18001 sites

$\begin{array}{ll}C+1 & 3 \\ C+1 & 3 \\ 1 & 2 \\ 1 & 2 \\ 2 & 4 \\ 1 & 2 \\ 1 & 2 \\ 1 & 2\end{array}$

verification

$5-7$

$5-7$

3

$3-4$

34

C, compulsory element; EMS, environmental management system; EPD, environmental product declaration; OHSAS, occupational health and safety management system. Numbers indicate points awarded for compliance with each tier of each clause. For section 3.4, all clauses follow a standard methodology, with first tier points awarded for the setting of a policy and metrics, second tier points awarded for the setting of objectives and targets, third tier points for reporting performance to stakeholders and top tier points awarded for external verification of these reported figures. The exceptions are clauses 3.4.3 and 3.4.6. Clause 3.4.3 for resource use does require as a mandatory element that a policy and metrics are set, but additional points are awarded for being able to demonstrate environmental stewardship at the source of constituent materials: 3 points for $60 \%$ traceability, 5 for $75 \%$ and 7 for $90 \%$. Clause 3.4.6 for LCA awards points based on whether the organisation has developed any type of environmental label for their assessed product, with 2 points awarded for the development of a type I or type II environmental label, 4 points awarded for a type III environmental label, or EPD, and five points awarded for reporting the results of this EPD to stakeholders.

Table 1. Structure of BES 6001 (adapted from BRE (2009))

organisation did not score. It would be expected that the higher a certificate performs in a given clause, the higher the overall performance will be against the standard. Anecdotal evidence suggests that there may be instances within the data, however, where certificates have performed strongly under certain clauses but have achieved a low OAS and vice versa, therefore leading to the first hypothesis proposed for this study.

Hypothesis 1: Scoring highly in some clauses within section 3.4 of BES 6001 correlates to a high overall performance against the standard
To derive overarching conclusions around performance against the standard for a group of certificates, it is important that the data are reliable and that any conclusions can be stated with confidence. For example, all other things being equal, if one certificate for a small precast concrete manufacturer obtains a given level of performance under waste management, then it should be expected that another, similar, company would score similarly under the same clause. If an individual clause is selected at random, it should produce a score that is consistent with the OAS for that certificate. If this were the case, it would then be said to have a good level of reliability. A means of 
LOA and points required to achieve

\begin{tabular}{lcccc}
\cline { 2 - 4 } Section & Excellent & Very Good & Good & Pass \\
\hline 3.2 and 3.3 total & 8 & 5 & 3 & Compulsory points \\
3.4 & 36 & 26 & 16 & 7
\end{tabular}

Table 2. Threshold scores required to achieve OAS in BES 6001

(adapted from BRE (2009))

looking at reliability is through gauging measures of internal consistency, which describes the extent to which all items in a test measure the same concept (Santos, 1999). The higher the measure of internal consistency, the more reliable the scale and hence the more confidence with which we can make a statement that would suggest that a high performer in an individual randomly selected clause would be consistent with high overall performance. To obtain a higher OAS, and hence a higher LOA, certificates have to score highly in individual clauses consistently across all eight clauses in order to accumulate enough points. Therefore, the second hypothesis is proposed as follows.

Hypothesis 2: The higher the level of attainment, the greater the internal consistency within the results.

BES 6001 (BRE, 2008, 2009) covers a number of environmental and social issues (section 3.4). Traditional organisational engagement with sustainability has focused largely on environmental issues, although this can be extended to cover social and economic dimensions (Ahi and Searcy, 2013). There is a considerable body of literature that considers environmental management practices of organisations, particularly with reference to environmental management system (EMS) certification to ISO 14001 (BSI, 2004) (e.g. Brammer et al., 2012; Daddi et al., 2011; Hofmann et al., 2012; Uhlaner et al., 2012). A EMS requires an organisation to identify significant environmental aspects and impacts, such as waste, water use and greenhouse gas (GHG) emissions. Given that some clauses within section 3.4 of BES 6001 would in many cases be covered by the operation of a EMS (mandatory for BES 6001 anyway), we can arrive at our third and final hypothesis.

Hypothesis 3: BES 6001 clauses that draw information from an organisation's environmental management system result in a greater number of higher scores than those which do not.

\section{Method}

There are four UK certification bodies that offer certification to BES 6001 (BRE, 2008, 2009) - the BRE, British Standards Institution (BSI), Construction Products Certification (CPC) and Complete Integrated Certification Services (CICS, rebranded as Lucideon since data were collected). Assessment score data from these certification bodies were obtained, including product certified, OAS and corresponding LOA and approximate company size (number of employees). In total, 138 different scores were obtained from 106 BES 6001 certificates; 25 of these certificates were assessed against version 1 of BES 6001 (BRE, 2008) and 81 of these certificates were assessed against version 2 (BRE, 2009). For analysis purposes, all certificates were grouped together given that the differences between each version are minimal. Due to confidentiality, however, information relating to company size for 24 of these certificates was unavailable, thus reducing the sample size to 114 scores from 82 certificates for these data. Furthermore, some products could not be classified into one of the broad product categories used in this study, thus reducing the sample size to 109 for analysis of the data.

The data were then categorised according to three criteria

$$
\begin{aligned}
& \text { six broad product groups } \\
& \text { three LOA (both listed in subsequent sections) } \\
& \text { SME and non-SME categories. }
\end{aligned}
$$

Of particular interest were scores obtained in section 3.4 of BES 6001 (BRE, 2008, 2009), which considers performance under environmental and social requirements.

Spearman's $\rho$ was used to determine how individual clause score correlates with total assessment score for each of the categories aforementioned. Spearman's $\rho$ is a measure of the strength of correlation that exists between two variables and is useful for analysing data that are not normally distributed. This study aimed to determine the correlation between individual clause score in section 3.4 of BES 6001 and total score obtained, and preliminary analysis indicated that the data were not normally distributed. Therefore, $\rho$ was selected as the most appropriate measure of correlation between the two variables.

Reliability analysis (i.e. Cronbach's alpha $(\alpha)$ ) was then used to gauge measures of internal consistency within the data. Internal consistency indicates how closely related a set of items are in a group, or their level of reliability. Analysis of reliability will 
determine in which, if any, of the individual clauses of the standard a high individual clause score corresponds to a high total score, and thus which clauses could be seen as summary measures of performance. In this case, a reliable scale would be when two certificates that are the same in terms of the construct being measured (i.e. individual clause performance) score similarly overall (Field, 2013). $\alpha$ Ranges in value from 0 to $1-$ the higher the score, the more reliable is the generated scale (Santos, 1999). Figures for $\alpha$ were also obtained if each clause was removed from the scale; hence, we can see whether reliability was improved or reduced by including each clause within each scale.

\section{Results}

Data were analysed according to three methods: LOA, company size and product sector. The following subsections discuss these in turn.

\subsection{Level of attainment}

Here, 138 assessment scores were categorised according to the assessment rating of the certificates - eight pass certificates, 51 good certificates and 79 very good or excellent certificates. Only three excellent certificates were available, and so for data analysis these were amalgamated with the 76 very good certificates. Figure 1 shows that typical correlations for pass certificates are fairly high and are lower for good and very good/excellent certificates, implying that correlations between clause 3.4.3 for resource use and OAS and clause 3.4.6 for LCA and OAS are generally lower than for other clauses.

Table 3 shows $\alpha$ for the analysis of each LOA, and $\alpha$ value if each clause was removed from the scale, or excluded from the calculation. The $\alpha$ values for LOA indicate poor levels of reliability, with Table 3 suggesting that reliability of all three scales is improved if clauses 3.4.3 and 3.4.6 are removed, implying that high performance under these clauses does not

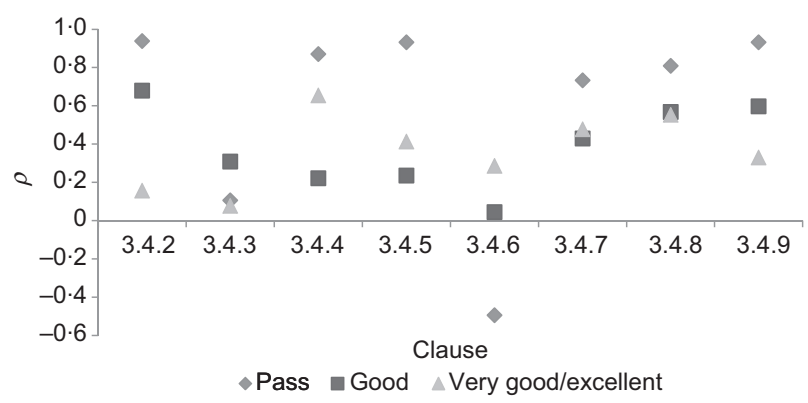

Figure 1. Spearman's $\rho$ correlations for each clause with overall score for certificates according to LOA; refer to Table 1 for clause headings 
typically correlate with high overall performance. In the case of good and very good/excellent certificates, $\alpha$ values are so low $(0 \cdot 117$ and $0 \cdot 192$, respectively) that even removing these clauses from the scale does not render the $\alpha$ value high enough to be considered reliable. For very good/excellent certificates, it is clear that clause 3.4.2 should also be removed from the scale. The results are consistent with those in Figure 1, where the exclusion of clauses that correlate more poorly with the overall score from the scale improves internal consistency, and hence reliability.

\subsection{Company size}

Data were also sorted by company size, categorised by SME or non-SME classification. The classification of a SME is based on the European Commission definition as an organisation with less than 250 employees and an annual turnover of under $€ 50$ million (approximately $£ 41$ million) (EC, 2005). One hundred and fourteen assessment scores were analysed, and the results are shown in Figure 2. Data from 15 SME certificates and 99 non-SME certificates were available.

Figure 2 suggests, as with the results for LOA, that correlation coefficients for clause 3.4.3 for resource use and clause 3.4.6 for LCA exhibited are lower than for other clauses. Clause 3.4.4 for waste management produced the strongest correlation coefficient for non-SMEs, with clause 3.4.9 for local communities exhibiting the highest correlation coefficient for SMEs. Clauses 3.4.4 and 3.4.5 also correlate relatively highly with the overall score for both SMEs and non-SMEs.

Cronbach's $\alpha$ values for company size (Table 4) indicate poor levels of reliability for both categories, with SME reliability improving if clause 3.4.3 for resource use and clause 3.4.6 for LCA are removed from the scale. For non-SME companies, only the removal of clause 3.4.6 results in increased reliability of the scale. $\alpha$ values were higher for the SME category, showing that, typically, the overall score obtained constitutes a better summary measure of performance for the SME category

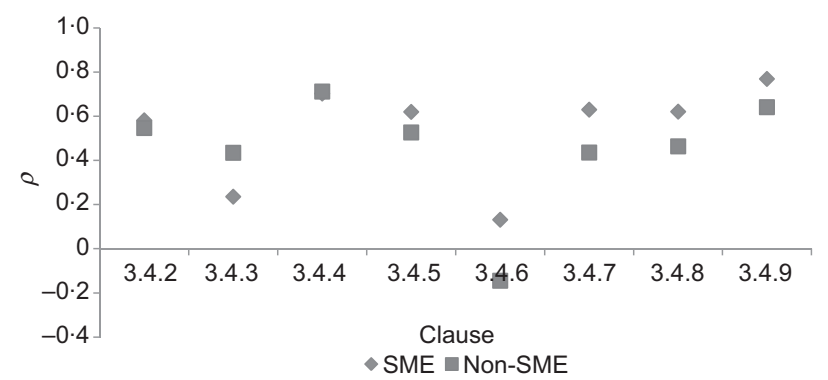

Figure 2. Spearman's $\rho$ correlations for each clause with overall score for certificates according to company size 
Engineering Sustainability

Volume 168 Issue ES2
Analysis of responsible sourcing

performance in BES 6001

certificates

Upstill-Goddard, Glass, Dainty and

Nicholson than for larger companies, although these $\alpha$ values may still be regarded as unreliable (Field, 2013).

\subsection{Product groups}

Six broad product groups were identified and certification scores grouped accordingly. Figures 3 and 4 show the results. Data from eight aggregate, seven asphalt, 46 brick, nine cement, 31 concrete and eight steel certificates were available. Figures 3 and 4 show instances of high and low correlation coefficients for each product sector. However, performance under each clause differs between sectors, with some performing highly under clauses where others do not. Most poor or negative correlations are under clause 3.4.6 for LCA, although, on the whole, correlations for clause 3.4 .3 for resource use are also too low to warrant further analysis.

Values for $\alpha$ (see Table 5) also indicate poor reliability in most cases, with the exceptions being cement and steel, which both return $\alpha$ values of more than 0.7 , indicating good internal consistency (Field, 2013). Table 5 indicates that reliability improves in most cases if clause 3.4.6 is removed. It also shows that $\alpha$ values increase in three of the six product groups if clause 3.4.3 is removed (i.e. these clauses do not constitute good summary measures of performance). The other four product groups return low $\alpha$ figures, suggesting very poor reliability.

\section{Discussion}

The results indicate that, consistently, clauses 3.4 .3 for resource use and 3.4.6 for LCA produce the poorest correlation coefficients with OAS, relative to how other clauses correlate with OAS. These clauses also exhibit very low or negative correlations with all other clauses; typically these are positive, albeit often weak, suggesting that as performance in one clause increases, performance in another clause also increases, thus leading to the conclusion that hypothesis 1 can be supported. Generally, performance in certain clauses does tend to correlate

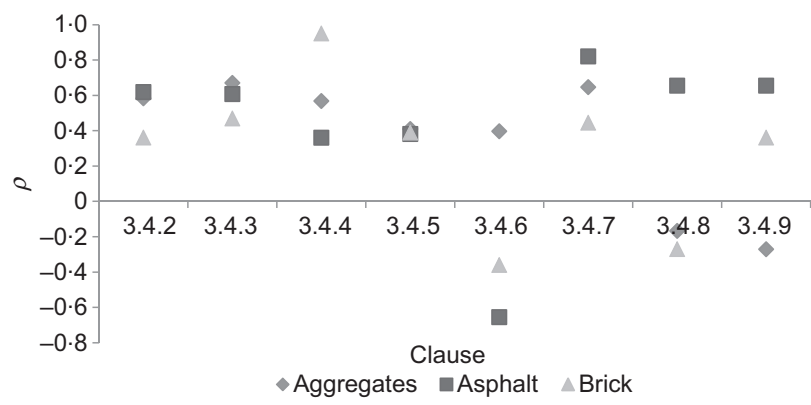

Figure 3. Spearman's $\rho$ correlations for each clause with overall score for certificates according to the aggregates, asphalt and brick product sectors

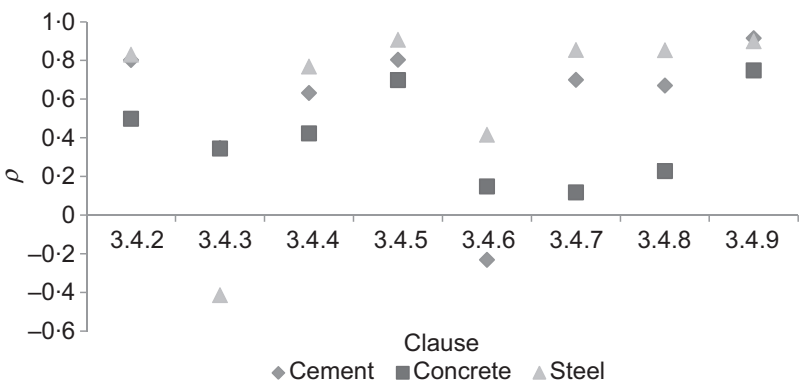

Figure 4. Spearman's $\rho$ correlations for each clause with overall score for certificates according to the cement, concrete and steel product sectors

with total score, but overall performance does not tend to depend on scores within clauses 3.4.3 and 3.4.6. In certain cases, high performance in these clauses is actually to the detriment of total score.

The significance of these findings can also be characterised in terms of current industry practice. Developing a LCA for an organisation's products (as required by clause 3.4.6 of BES $6001)$ is an intensive process and, relative to the other points available in BES 6001 (BRE, 2008, 2009), is much more difficult to obtain. Zackrisson et al. (2008) noted that a key problem with obtaining wider uptake of LCA and environmental product declarations (EPD) is the significant cost and time involved. Therefore, organisations may favour other clauses and aim for high performance under these to ensure they accumulate enough points to reach their desired LOA. So, LCA may be thought of as a clause that organisations will only attempt if they require additional points to reach their target LOA; this finding is supported by the data, with $98 / 138(71 \%)$ of the certificates scoring zero for the LCA clause. It is also interesting that the LCA clause usually correlates negatively with other clauses (the exception being in the steel product sector where correlations were generally positive). Furthermore, it was observed in pass certificates that higher performing certificates did not score for the LCA clause, yet lower overall performers all scored under part (a) of this clause. This provides further evidence that focusing on points under the LCA clause may be to the detriment of performance in other clauses, and indeed overall performance. Most construction product manufacturers do not hold third-party LCA data (Glass, 2012), and evidence indicates that it should be removed from the RS agenda (BRE Global, 2013) and promoted as a separate entity by way of EN 15804 (BSI, 2012). Yet Jeswani et al. (2010) argue that LCA should be broadened by integrating with other methods of sustainability assessment. Although it is recognised that doing this by way of RS could be useful for addressing the three pillars of sustainability, the results of this study show that there is a 
Analysis of responsible sourcing

performance in BES 6001

certificates

Upstill-Goddard, Glass, Dainty and

Nicholson

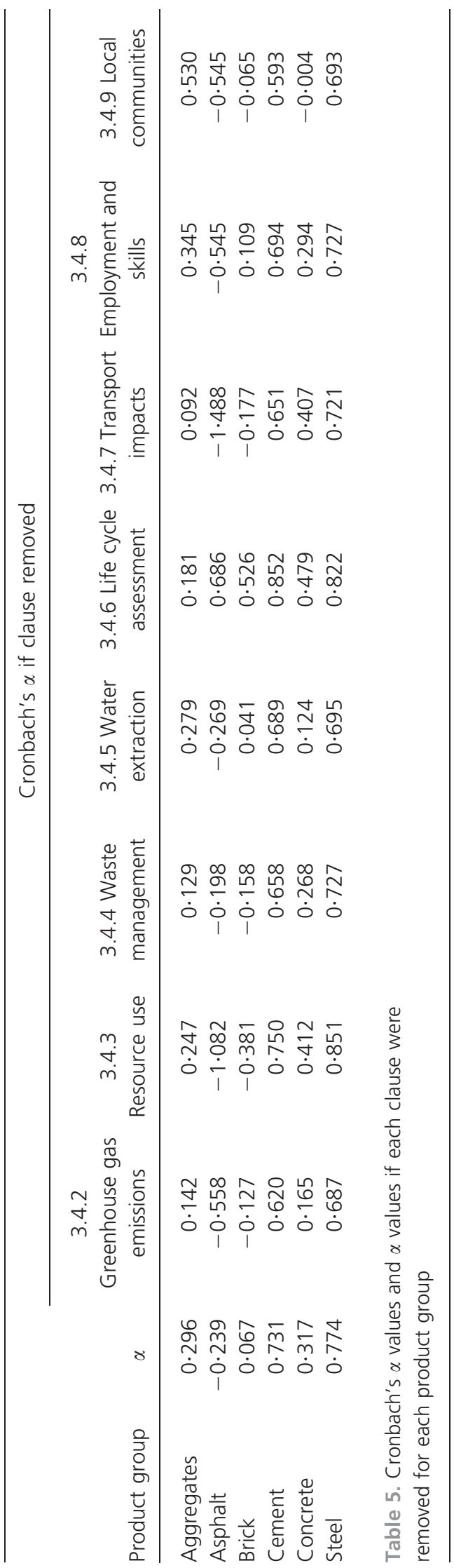

mismatch between the two agendas. Furthermore, there is clear potential for LCA studies to provide object-oriented (environmental parameter) data within building information models (BIMs) in due course, and as such it could be expected that construction industry actors will increase their engagement with LCA in future years.

The findings for LCA are also relevant when revisiting hypothesis 2 . As suggested by the $\alpha$ values, internal consistency within the results is low - only analysis by product sector produces $\alpha$ values greater than $0.7(0.774$ for steel and 0.731 for cement). $\alpha$ Values do not appear to be higher for higher levels of attainment, with good and very good/excellent certificates revealing especially low $\alpha$ values $(0 \cdot 117$ and $0 \cdot 192$, respectively), indicating that these scales should not be deemed reliable. What the data do appear to suggest fairly consistently is that removing either clause 3.4 .3 for resource use or clause 3.4.6 for LCA from the scale would result in increased internal consistency. Values for $\alpha$ indicate that removal of clause 3.4.6 in all cases (except for aggregates in the product group analysis) will increase reliability, suggesting that this clause is not a good summary measure of performance. It can therefore be shown that specifiers looking to determine whether a supplier has carried out a LCA or holds a EPD should perhaps not consider using BES 6001 (BRE, 2008, 2009) certification status as a means of extracting LCA data, as these findings indicate that certificates with a high OAS, and hence LOA, do not necessarily mean that the LCA clause has been scored well, if indeed at all. Instances of very good/excellent certificates scoring the LCA clause are considerably low (24\% (19/79)). Ortiz et al. (2009) found that applying LCA can be very important in achieving sustainable development for the construction industry, yet the results obtained here do not support this. The low levels of engagement with LCA observed suggest that current construction practices in this area are perhaps not sufficiently advanced. However, as this is based only on LCA data within BES 6001 (BRE, 2008, 2009) certificates, it does not capture the entire industry's current engagement with EPD, so further research is required. Furthermore, the BRE-maintained Green Book Live (BRE, 2014b) resource provides information on EPD certificates to EN 15804 (BSI, 2012) and generic information on its environmental profiling scheme, so specifiers should consider consulting such a resource to obtain information on suppliers that are able to provide compliant LCA data.

The findings also appear to support hypothesis 3. Certification to BES 6001 (BRE, 2009) requires that an organisation has in place, as a mandatory requirement, a fully operational EMS, either following the principles of, or certified to, ISO 14001 (BSI, 2004). In many cases, issues within section 3.4 of BES 6001 (BRE, 2009) overlap with environmental aspects identified by an organisation's EMS. It was generally observed that 
Engineering Sustainability

Volume 168 Issue ES2
Analysis of responsible sourcing

performance in BES 6001

certificates

Upstill-Goddard, Glass, Dainty and

Nicholson performance under these areas was relatively high, which is likely because many applicant organisations had monitoring processes in place. Clause 3.4.2 for GHG emissions is particularly interesting; not only are emissions of GHG often covered in an organisation's EMS, but many heavy industries, including cement, are obliged to comply with the EU emissions trading scheme (ETS) (EC, 2013), for which demonstrating annual EU ETS reports will result in organisations being awarded maximum points under clause 3.4.2.

Clause 3.4.3 for resource use does not correlate with LOA and should also not be considered as a summary measure of performance. The clause is arguably relatively easily achieved anecdotal evidence indicates that suppliers holding a ISO 14001 (BSI, 2004) certified EMS and an explicit statement around resource efficiency in their environmental policy are classified as a 'traceable source' for this clause. BES 6001 (BRE, 2008, 2009) auditors have suggested that downloading and retaining a supplier's corporate social responsibility report where the aforementioned practices are discussed would be satisfactory to be deemed 'traceable'. Furthermore, under version 2 of BES 6001 (BRE, 2009), this statement was not required to be verified or approved, implying that where organisations could not demonstrate ISO 14001 (BSI, 2004) certification and a relevant policy statement in any part of their supplier base, obtaining some type of stewardship statement from their suppliers that covered issues such as resource efficiency and protection of biodiversity could be deemed as verification of environmental stewardship at that material's source. Indeed, there is a high proportion of certificates scoring maximum points here. Interestingly, version 3 of BES 6001 (BRE, 2014c) added the requirement for such statements to be externally verified, implying that, unlike under version 2, simply obtaining a short statement from suppliers will not be satisfactory for demonstrating stewardship at source, unless it has been verified by a third party. Perhaps this indicates that requirements under version 2 were rather too easy to obtain credit for, and as such did not present an examination of an organisation's supply chain with a sufficient level of rigour or consistency. Alternatively, it may simply indicate that industry expectations have increased in the meantime.

It is also significant that clause 3.4.3 (along with clause 3.4.2) holds heavier weightings than other clauses within this section, with a maximum of seven points available. It is also mandatory, so organisations are obliged at least to develop a policy and metrics. Considering the earlier point made regarding LCA, it is possible that organisations focus more on this clause because it holds richer rewards in terms of points and therefore contributes more towards an organisation's target points tally. However, it could also be argued that undertaking research into supplier environmental stewardship practices could also be time consuming (particularly for a SME where access to resources has already been noted as a challenge). This is supported by the results in the SME category, where the correlation coefficient between clause 3.4.3 and total score is lower than for non-SMEs. Further, removing clause 3.4.3 from the scale in the case of SMEs increases $\alpha$ to 0.706, which is considered a reliable scale (Field, 2013).

\section{Conclusion, limitations and recommendations for future work}

An analysis of performance in BES 6001 (BRE, 2008, 2009) certificates for RS between 2008 and 2013 has been presented. The results indicate that correlation coefficients and Cronbach's $\alpha$ values are relatively low, suggesting that, generally, high performance in individual clauses of BES 6001 does lead to higher overall performance in some cases, but that scoring mechanisms cannot be said to be reliable for determining a summary measure of performance. The scoring patterns suggest that organisations tend not to approach certification in a methodical way; rather there are different approaches at the company level. This is affected by management of the various social and environmental issues assessed within BES 6001, yet it remains surprising that even relatively straightforward issues to manage, such as waste and GHG emissions - often considered in an organisation's EMS - still return low (although relatively higher in the context of this study) correlation coefficients and $\alpha$ values.

These data imply an apparent lack of a strategic approach to certification to the standard, and organisations are largely reactive in their response to it, favouring those clauses that are covered by existing management systems, which contain relatively easy to obtain points or are reflected by current industry practice. This is supported by De Colle et al. (2014) who found that organisations often implement standards without adaptation to their specific needs and characteristics, potentially causing detrimental effects. Through use of an example, they suggest organisations seek high scores in those indicators that it is easiest to score against with little consideration of how important they are to overall performance. Clearly, if the standard poses a particular challenge for some applicant organisations (e.g. in terms of cost, resources and time), then differing practices and priorities at the organisational level may influence the organisation's ultimate performance against BES 6001 (BRE, 2008, 2009). Hence, there remains an unanswered question regarding the suitability of the standard for construction material suppliers and product manufacturers.

Despite the unique nature and novelty of this study, there are limitations. First, the dataset is small. When split into individual categories (such as by product), the datasets are even smaller and therefore conclusions, although relevant and significant, are based on only a small snapshot of the construction products industry. For some datasets, it was difficult to draw robust conclusions due to sample size. Stevens et al. (2012) question the 
Engineering Sustainability

Volume 168 Issue ES2
Analysis of responsible sourcing

performance in BES 6001

certificates

Upstill-Goddard, Glass, Dainty and

Nicholson usefulness of dividing data by company size by way of the broad categories of SME and non-SME, for example. Although it is acknowledged that there are considerable differences and variations within each of these categories, the small size of the dataset meant that drawing valid conclusions would be difficult if we were to abide fully by the recommendation of Stevens et al. (2012). Future work could consider a sample of BES 6001 (BRE, 2008,2009 ) certifications in greater depth, and pose questions as to why performance patterns are observed.

A major criticism of BES 6001 (BRE, 2008, 2009) version 2 certificates was their lack of transparency with regard to individual clause scores obtained by certified product manufacturers. Version 3 BES 6001 (BRE, 2014c) certificates will also include the scores obtained against the standard as an addendum. Potentially, these data could feed into BIMs in due course, although it is recognised that such an innovation may be some time coming as the industry continues to evolve its building information modelling agenda.

\subsection{Practical relevance}

The findings have a number of implications for industry. The results suggest that a material specifier should not assume that LCA status of a supplier will be covered by an organisation's BES 6001 (BRE, 2008, 2009) certificate. Similarly, they should not look at performance under the resource use clause and deem external verification of environmental stewardship from an organisation's suppliers a reliable summary measure of performance. The scores achieved under this clause, when compared with those of other clauses, suggest that this clause is perhaps the single 'lowest hanging fruit' and that this distorts the picture somewhat. High performance here may result in an organisation achieving a higher LOA than their performance under other clauses would perhaps suggest. These are also key findings for the BRE. Moreover, if BES 6001 (BRE, 2008, 2009) was an easy standard to achieve certification to, it would be expected that correlations and internal consistencies would be high. However, the low internal consistencies and correlations between clause and total score are evidence that, generally, applicant organisations struggle to address the full breadth of issues covered by the standard in a consistent and comprehensive way. This may mean that the demands of BES 6001 (BRE, 2008, 2009) are too onerous for some organisations.

\section{Acknowledgements}

This research forms part of an engineering doctorate (EngD) programme sponsored by Responsible Solutions Ltd and the Engineering and Physical Sciences Research Council (EPSRC), which is managed through the Centre for Innovative and Collaborative Construction Engineering (CICE), based at the School of Civil and Building Engineering at Loughborough University. The BRE provided feedback and comments during the drafting of this paper and, along with the BSI, CPC and
CICS (now Lucideon), provided all the data used in this research. The support of all these parties is gratefully acknowledged.

\section{REFERENCES}

Ahi P and Searcy C (2013) A comparative literature analysis of definitions for green and sustainable supply chain management. Journal of Cleaner Production 52(1): 329-341.

BDA (Brick Development Association) (2012) Brick Industry: Sustainability Strategy Progress Report 2012. See http:// www.brick.org.uk/wp-content/uploads/2013/01/ Sustainability-Strategy-Progress-Report-2001-2012-webreduced.pdf (accessed 13/02/2014).

BERR (Department for Business, Enterprise and Regulatory Reform) (2008) Strategy for Sustainable Construction. BERR, London, UK.

BIS (Department for Business, Innovation and Skills) (2013) Construction 2025 - Industrial Strategy: Government and Industry in Partnership. BIS, London, UK.

Brammer S, Hoejmose S and Marchant K (2012) Environmental management in SMEs in the UK: Practices, pressures and perceived benefits. Business Strategy and the Environment 21(7): 423-434.

BRE (Building Research Establishment) (2008) BES 6001: Issue 1.0 Framework Standard for the Responsible Sourcing of Construction Products. BRE, Watford, UK.

BRE (2009) BES 6001: Issue 2.0 Framework Standard for the Responsible Sourcing of Construction Products. BRE, Watford, UK.

BRE (2011) Breeam New Construction - Non-Domestic Buildings: Technical Manual SD5073-2.0:2011. BRE, Watford, UK.

BRE (2014a) Responsible Sourcing of Construction Products (BES 6001): Event Details. See http://www.bre.co.uk/ eventdetails.jsp?id=7723 (accessed 01/03/2014).

BRE (2014b) Green Book Live: Responsible Sourcing of Construction Products (BES 6001). See http://www. greenbooklive.com/search/scheme.jsp?id=153 (accessed 20/ 02/2014).

BRE (2014c) BES 6001: Issue 3.0 Framework Standard for the Responsible Sourcing of Construction Products. BRE, Watford, UK.

BRE Global (2013) Product Category Rules for Type III Environmental Product Declaration of Construction Products to EN 15804: 2012. See http://www.bre.co.uk/ filelibrary/Materials/BRE_EN_15804_PCR.PN514.pdf (accessed 15/04/2014).

BSI (2004) BS EN ISO 14001:2004: Environmental management systems - requirements with guidance for use. BSI, London, UK.

BSI (2007) BS OHSAS 18001 Occupational health and safety management. BSI, London, UK. 
Engineering Sustainability

Volume 168 Issue ES2
Analysis of responsible sourcing

performance in BES 6001

certificates

Upstill-Goddard, Glass, Dainty and

Nicholson
BSI (2012) BS EN 15804:2012: Sustainability of construction works - core rules for the product category. BSI, London, UK.

Ceequal (2013) The Sustainability Assessment, Rating and Awards Scheme for Civil Engineering. See http://www. ceequal.com/ (accessed 04/03/2014).

CPA (Construction Products Association) (2014) Welcome to the Construction Products Association. See http://www. constructionproducts.org.uk/ (accessed 18/02/2014).

Daddi T, Magistrelli M, Frey M and Iraldo F (2011) Do environmental management systems improve environmental performance? Empirical evidence from Italian companies. Environment, Development and Sustainability 13(5): 845-862.

DCLG (Department for Communities and Local Government) (2006) Code for Sustainable Homes: A Step Change in Sustainable Home Building Practice. DCLG, London, UK.

De Colle S, Henriques A and Sarasvathy S (2013) The paradox of corporate social responsibility standards. Journal of Business Ethics 125(2): 177-191, http://dx.doi.org/10.1007/ s10551-013-1912-y.

EC (European Commission) (2005) The New SME definition User Guide and Model Declaration. See http://ec.europa.eu/ enterprise/policies/sme/files/sme_definition/ sme_user_guide_en.pdf (accessed 25/02/2014).

EC (2013) The EU Emissions Trading Scheme (EU ETS) Factsheet. See http://ec.europa.eu/clima/publications/docs/ factsheet_ets_en.pdf (accessed 03/02/2014).

Field A (2013) Discovering Statistics Using IBM SPSS Statistics, 4th edn. Sage, London, UK.

Ghumra S, Glass J, Frost MW, Watkins M and Mundy J (2011) Materials and energy assessment in Ceequal transport projects. Proceedings of the Institution of Civil Engineers Transport 164(3): 153-164.

Glass J (2011) Briefing: Responsible sourcing of construction products. Proceedings of the Institution of Civil Engineers Engineering Sustainability 164(3): 167-170.

Glass J (2012) The state of sustainability reporting in the construction sector. Smart and Sustainable Built Environment 1(1): 87-104.

Glass J, Achour N, Parry T and Nicholson I (2012) Engaging small firms in sustainable supply chains: responsible sourcing practices in the UK construction industry. International Journal of Agile Systems and Management 5(1): 29-58.

Hofmann KH, Theyel G and Wood CH (2012) Identifying firm capabilities as drivers of environmental management and sustainability practices - evidence from small and mediumsized manufacturers. Business Strategy and the Environment 21(8): 530-545.

Jeswani HK, Azapagic A, Schepelmann P and Ritthoff M (2010) Options for broadening and deepening the LCA approaches. Journal of Cleaner Production 18(2): 120-127.

Lee SY and Klassen RD (2008) Drivers and enablers that foster environmental management capabilities in small- and medium-sized suppliers in supply chains. Production and Operations Management 17(6): 573-586.

Ortiz O, Castells F and Sonnemann G (2009) Sustainability in the construction industry: A review of recent developments based on LCA. Construction and Building Materials 23(1): 28-39.

Santos JRA (1999) Cronbach's alpha: A tool for assessing the reliability of scales. Journal of Extension 37(2): 1-5. See http:// www.joe.org/joe/1999april/tt3.php (accessed 14/01/2014).

SCF (Sustainable Concrete Forum) (2010) Concrete Industry Guidance to Support BES 6001: Issue 3. SCF, Camberley, UK.

SCF (2012) Responsible Sourcing and the Concrete Industry. See http://apres.lboro.ac.uk/docs/Nov2012_Slater.pdf (accessed $13 / 02 / 2014)$.

Sev A (2009) How can the construction industry contribute to sustainable development? A conceptual framework. Sustainable Development 17(3): 161-173.

SFGB (Stone Federation Great Britain) (2012a) Demonstrating Your Company's Sustainability Credentials. SFGB, Folkestone, UK.

SFGB (2012b) Natural Stone: The Sustainable Solution. SFGB, Folkestone, UK.

Stevens PA, Batty WJ, Longhurst PJ and Drew GH (2012) A critical review of classification of organisations in relation to the voluntary implementation of environmental management systems. Journal of Environmental Management 113(1): 206-212.

TCC (The Concrete Centre) (2014) BES 6001. See http://www. concretecentre.com/codes_standards/bes_6001.aspx (accessed 13/02/2014).

Uhlaner LM, Berent-Braun MM, Jeurissen RJM and de Wit G (2012) Beyond size: Predicting engagement in environmental management practices of Dutch SMEs. Journal of Business Ethics 109(4): 411-429.

Young J and Osmani M (2013) Investigation into contractors' responsible sourcing implementation practice. Proceedings of the Institution of Civil Engineers - Engineering Sustainability 166(6): 320-329.

Zackrisson M, Rocha C, Christiansen K and Jarnehammar A (2008) Stepwise environmental product declarations: ten SME case studies. Journal of Cleaner Production 16(17): 1872-1886.

\section{WHAT DO YOU THINK?}

To discuss this paper, please email up to 500 words to the editor at journals@ice.org.uk. Your contribution will be forwarded to the author(s) for a reply and, if considered appropriate by the editorial panel, will be published as discussion in a future issue of the journal.

Proceedings journals rely entirely on contributions sent in by civil engineering professionals, academics and students. Papers should be 2000-5000 words long (briefing papers should be 1000-2000 words long), with adequate illustrations and references. You can submit your paper online via www.icevirtuallibrary.com/content/journals, where you will also find detailed author guidelines. 